\title{
Factor Analysis of Job Satisfaction in the Construction Industry.
}

\author{
E.O. Aiyewalehinmi \\ Department of Civil Engineering, \\ The Federal University of Technology,Akure.
}

\begin{abstract}
This paper presents a Factor Analysis (FA) carried out on the responses of the four major construction parties to the questionnaire. Involved are:management, employer's association, employees, and Construction Trade Union. Underlying the dimension (factors) of the responses data for the four parties are compared and findings are discussed. The influence of various contextual factors on some of these relationships and perceptions between/among the four major construction parties is investigated. A number of essential dimensions of workplace variables are identified which form the basis for developing both conceptual and research model. A significant understanding of group'sinsights of workplace communication and industrial relations(IR) is obtained. The purpose of factor analysis is to develop factors which identity the major dimensional differences within the data set. Finally, the study investigates the statistical reliability of the sample data; a reliability scale assessment indicates that results obtained from the statistical analysis are indeed valid. Keywords: Satisfaction, Management, Employer's Association, Non-Management Employees and Union.
\end{abstract}

\section{INTRODUCTION}

The belief that industrial disputes are in some way a natural consequence of job satisfaction in the construction is widely spread among researches and academics. Indeed, job satisfaction theory has even been employed as a criterion to measure the valid of work attitude and success of organizational change.In an attempt to gain insight into this subject, Argyle (1972) asserts that workers who are happy with their job will attend work regularly and permanently. His idea is based on the Human Relations School's over simplicity prescription. Hill and Trist (1955) through their withdrawal theory, explains trends towards absence, turn over, accident, association and employees length of service. However, there are a few writers such as Tiffin McCormick(1996) who hadreviewedrelevant literatures and do not share the same view as other author. They stress the relationship between job satisfaction and absenteeism should not be generalized. In this sense, it is important to understand factors determining job satisfaction, although they are not simplyexact opposite of those contributing to job satisfaction.

Satisfaction and dissatisfaction stem fromvarious roots. Smith, R.and Roth, D. (1991) investigate the following factorsas major causes of job satisfaction; pay, work, promotion, supervision,co-workers including Safety. Maloney and McFellen (1998)explained that satisfaction with intrinsic factor contributes to job satisfaction. They went further to say those job outcomes which are directly related to performing a task can be termed "intrinsic outcomes" and those that are allocated to (by) others signified "extrinsic outcomes". Performing a task requires one to make use ones skills and abilities which provides that intrinsic outcomes. On the other hand, satisfaction is a function of job outcomes both desired and expected. Therefore those workers who achieve the outcomes their expected tend to be satisfied with their work.

\section{THE RESEARCH APPROACH}

The research Methodology is designed specifically to determine how to improve work communication between employers and employees/ trade union. New South Wales was selected as the area which the data was collected. Mail questionnaires were sent to 42 construction industries defined as Management, 80 nonmanagement employees, 30 employers' Associations defined as Managing Director and Executives and 15 Building and Construction Workers' Union Officials, defined as Union were contacted in New South Wales, Australia as a means of data collection and response were analyzed using a Standard Statistical Package (SPSS) Statistical Package for the Social Sciences; for window.Data was limited to New South Wales because the participant parties are exposed to the same environmental working conditions.

\section{FACTOR ANALYSIS}

Elementary statistical analysis is concerned with finding the means and standard deviation (scattered) of variable values with discovery the differences between various means. Factor analysis is more radical departure from statistical associated with experimental tradition, in that it does not accept arbitrary choices as to what are important variable in any field. Factor analysis groups numerous possible variables into fewest possible single whole or holistic influences. It offers a comprehensive and sensitive method of expressing quantitative 
relations between variables from observation of co- variables. Furthermore, factor analysis is more systematic in that it first groups all variables, estimates their independent functional unities and then predicts their criterion.

\section{RELIABILITY}

Reliability assessment is appropriate for multi - item scales such as used in this study. Reliability increases multi -term scales by allowing measurement errors to cover each other.

\section{FACTOR ANALYSIS OF RESULTS}

The perceptions of each of the four respondent groups wasfactor analyzed using the principal component method with correlation matrix as input. The diagonal elements,initially the squared multiple correlations were iterated by forcing until the maximum change in communality estimates was less than 1 (see table 1.1 below). The Eigen value and cumulative proportion of the total variance were computed and rotations were based on the Oblin - Criterion utilizing normalization.

The Kaiser - Meyer - Olkin (KMO) method measures the sampling adequacy and comparesthe magnitudes of the partial correlations coefficients. These analyses were used to simplify the results to make them more meaningful and less difficult to interpret. All interpretations of factor loadings were based on individual items of 0.5 and above (see Table 1.1 below).

\section{FACTOR ANALYSIS OF JOB SATISFACTION.}

The results of factor analysis of items on the questionnaire for the simple individuals relating to job satisfaction appears in the table 1.1 and figures 1.1 below. Factors identified were based on factor loading 0.5 and above. All factor loadings which appear in the tables are positive. Positive loadingsallow more simple interpretations.In this regard it helps researchers to have a clear view of overall results. The extent to which the employees' factor grouping differs from management, employers' associations and union perception will indicate the extent to which is hypothesized.

Table 1.1 below shows the factor loading and communality coefficients extracted from the analysis of 15 items shown on the questionnaire for management employees' perception of job satisfaction. Only four factors had factor loading in excess of 0.5 and above and account for approximately $72.6 \%$ of the total variance obtained from management responding group. They are arranged according to the size of loading. The three dimensional plot of the loadings of the first three factors appear in figure 1.1.

Factor 1, clearly indicates a self-managing team with minimum supervision.

Factor 2 is associated with analytical techniques. An analytical skill is considered as ability to

workindependently with minimum supervision. Management respondent who scored highly on factor believe that employee satisfaction is related to analytical skills. Factor 3 has four items and is associated with internal satisfaction, described as responsibility. Factor4 comprise two items and appears to be associated with external satisfaction. It is defined as directionality accuracy. It seems that these four factors are associated with trust of minimum supervision. The responses of management indicate that job satisfaction goes with selfmanagement under minimum supervision. However, the result shows that, for management respondents, job satisfaction is associated with group commitment, minimum supervision and self - management within a team.

Table 1.1 Factor analyses of items relating to management perceptions of job satisfaction.Factor Loading

\begin{tabular}{|c|c|c|c|c|c|c|c|}
\hline Itemp & Lodingl & teplls & Lodingl & Item: & Loditis? & Atet: & Lodilig - \\
\hline $\mathrm{TS}$ & .896 & E & M. & $R$ & .1601 & $M$ & .497 \\
\hline II & .7186 & R & .77714 & $\mathrm{RS}$ & .189 & 312 & 6114 \\
\hline IA & .979 & 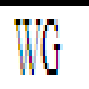 & 64.9 & TWE & 64.2 & & \\
\hline 176 & .9970 & & & 912 & 583 & & \\
\hline $\mathbb{E D D}$ & 6098 & & & & & & \\
\hline
\end{tabular}


Factor Analysis Of Job Satisfaction In The Construction Industry.
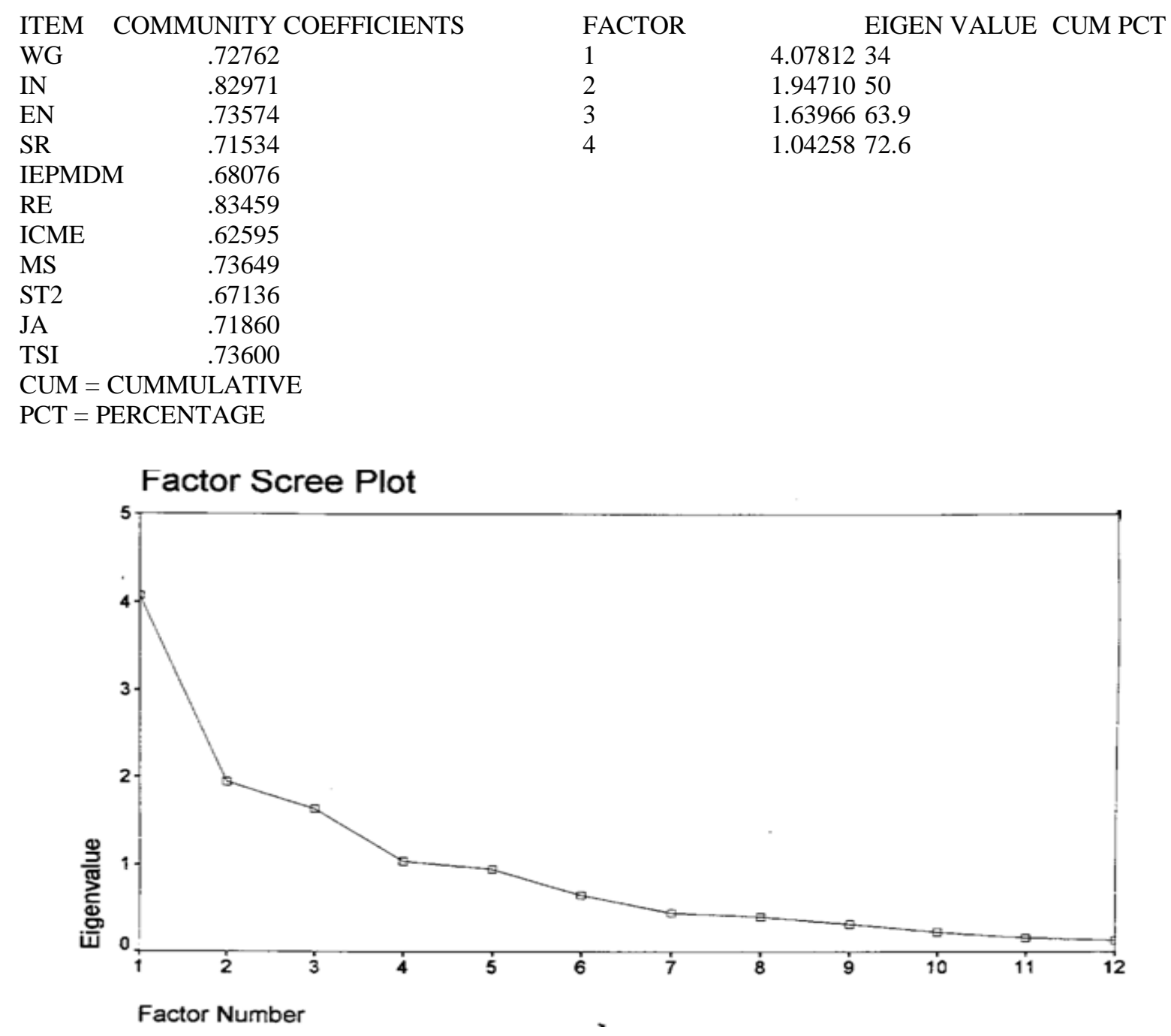

\section{Factor Plot in Rotated Factor Space}

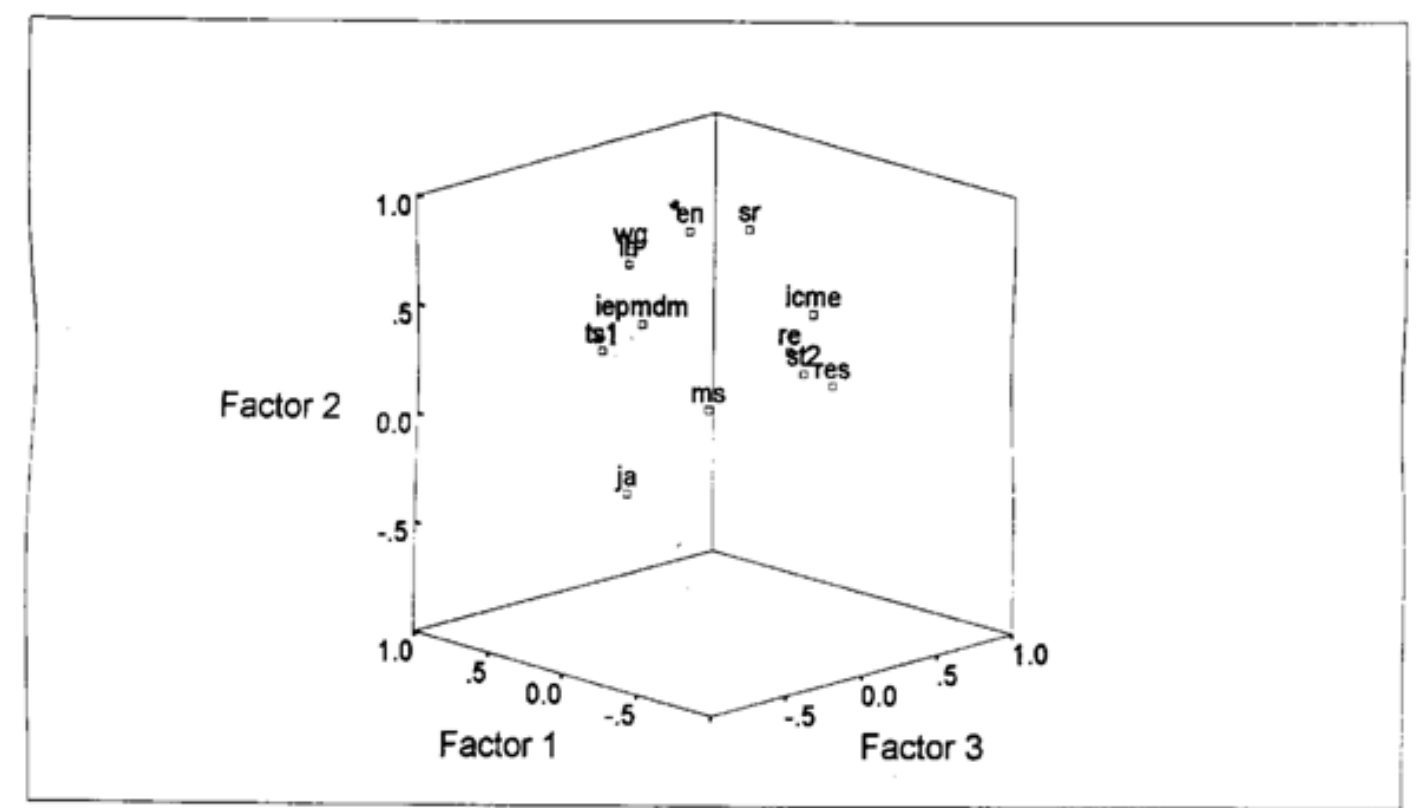

Figure 1.1 Rotated eigenvalue and varimax (3D) factor plot relating to management perceptions of job satisfaction. 
Table 1.2 presents factor loading of items and communality coefficients obtained from employee's perceptions of job satisfaction while figure 1.2 shows the three dimensional plot of the loading of the first factors and a screen plot of totalvariance (Eigen value) associated with each factor. Four factors were identified and items included in them, all have positive loading together accounting for approximately $75.6 \%$ of the total variance obtained from the group. Factor 1 comprises five items related to extrinsic satisfaction. Factor 1 clearly relates to an external influence associated with maximum supervision and is considered as denoting directionality and mobility aspiration. Factor2 consist of six items considered to be related to internal job satisfaction with minimum supervision. Factor 2 is spotted to signify self - managing teams. It can be tagged responsibility and directionality. Factor 3 includes two items clearly indicating social satisfaction. These elements are related to trust. Factor 3 is defined as commitment or loyalty. Factor 4 consists of two items related to internal satisfaction with minimum supervision. These are considered to be mobility, aspiration and directionality. Factor 4 is branded role of professionalism and appears to be connected with skills and experience. These four factors identified in the analysis of employees' perception of job satisfaction is related to work place communication. These factors are closely related to factors identified in equivalent factor analysis for management (table 1.1).

Table 1.2 Factor analyses of items relating to employees' perception of job satisfaction.

\begin{tabular}{|l|l|l|l|l|l|l|l|}
\hline Items & Loadings 1 & Items & Loadings 2 & Items & Loading 3 & Items & Loading 4 \\
\hline REC & .78336 & WG & .80499 & IEPMD & .78667 & MS & .87256 \\
\hline IS & .78144 & IN & .75873 & ICME & .75526 & RES & .61669 \\
\hline FB & .77901 & SR & .75462 & & & & \\
\hline ST & .71916 & FI & .69866 & & & & \\
\hline YS & .70860 & EN & .59596 & & & & \\
\hline & & JA & .56836 & & & & \\
\hline
\end{tabular}

$\begin{array}{lc}\text { COMMUNITY COEFFICIENTS } \\ \text { REC } & .80594 \\ \text { IS } & .78821 \\ \text { FB } & .77032 \\ \text { ST } & .70407 \\ \text { YS } & .65045 \\ \text { WG } & .74426 \\ \text { IN } & .78808 \\ \text { SR } & .76694 \\ \text { FI } & .70560 \\ \text { EN } & .73660 \\ \text { JA } & .76693 \\ \text { IEPMD } & .79182 \\ \text { ICME } & .76213 \\ \text { MS } & .84016 \\ \text { RES } & .71298 \\ \text { CUM = CUMMULATIVE } \\ \text { PCT = PERCENTAGE }\end{array}$

\section{FACTOR}

1

2

3

4
EIGEN VALUE CUM PCT

7.5313950 .2

1.6001760 .9

1.1440068 .5

1.0689175 .6

Factor Scree Plot

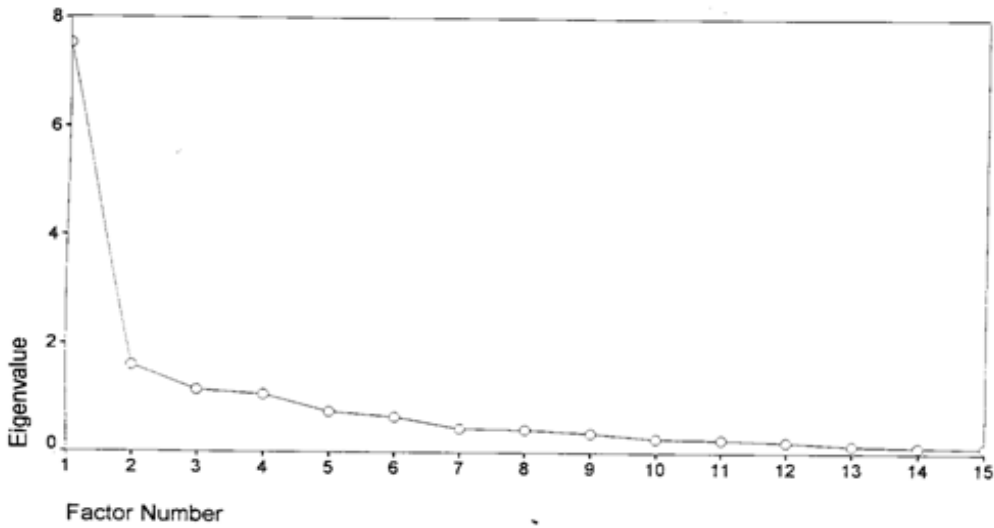




\section{Factor Plot in Rotated Factor Space}

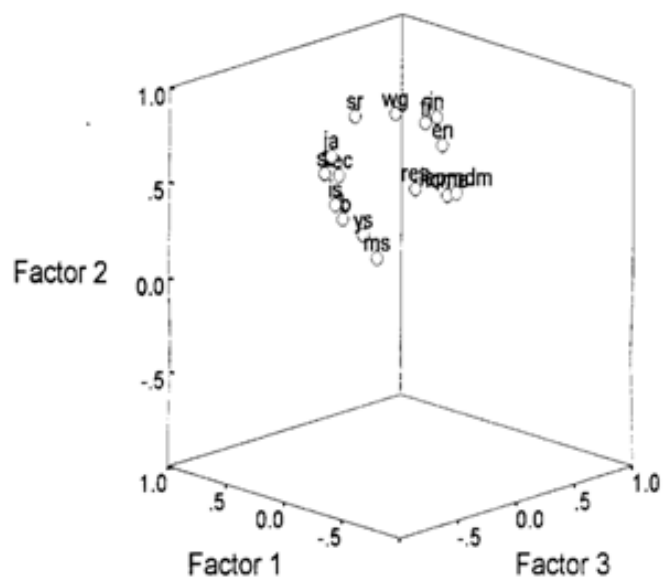

Figure 1.2 Rotated varimax (3D) factor plot and eigenvalue relating to employee perceptions of job satisfaction

Table 1.3 shows the factor loadings and communality coefficients obtained for employers Associated respondents in regard to job satisfaction variables in the questionnaire. Figure 1.3 illustrates three dimensional plot of the loading of the first three factors and screen plot of totalvariance(Eigen value) associated with each factor. Three significant factors were identified collectively they stand for $77 \%$ of the total variance obtained from the respondent group. Factor 1 includes five items considered to relate to a team satisfaction and selfmanaging with minimum supervision. These items are clearly associated with team performance and collaboration. Therefore factor 1 is labeled as directionality andinfluence. Factor 2 consists of three items considered to denote internal satisfaction which can be described as work role habit. High scores on work role habit in the construction industry indicate a clear failure on management side to provide employees with clear directives and means of completing a task. Role work habit also can be interpreted as both management and employees'behaviour towards one another. Factor 2 clearly signifies role ambiguity. The third factor has only intrinsic and extrinsic job satisfaction. These factors denote employees' ability to work independently with minimum supervision. Factor 3 can be described as indicating mobility aspiration and accuracy.

These factors undoubtedly represent workplace communication.

Table 1.3 Factor analyses of items relating to employers association perception of job satisfaction

\begin{tabular}{|l|l|l|l|l|l|}
\hline Items & $\begin{array}{c}\text { Loadings } \\
1\end{array}$ & Items & $\begin{array}{c}\text { Loadings } \\
2\end{array}$ & Items & $\begin{array}{c}\text { Loading } \\
3\end{array}$ \\
\hline WG & .84978 & REC & .88557 & FB & .78815 \\
\hline IEPMD & .81048 & ICME & .80591 & MS & .72792 \\
\hline IN & .80029 & SR & .78139 & FI & .67198 \\
\hline RES & .78857 & & & & \\
\hline EN & .75825 & \multicolumn{5}{|l}{} \\
\hline
\end{tabular}

$\begin{array}{lc}\text { ITEM } & \text { COMMUNITY COEFFICIENTS } \\ \text { WG } & .76964 \\ \text { IEPMD } & .81096 \\ \text { IN } & .74130 \\ \text { RES } & .81650 \\ \text { EN } & .78082 \\ \text { REC } & .85365 \\ \text { ICME } & .69706 \\ \text { SR } & .84120 \\ \text { FB } & .80689 \\ \text { MS } & .67228 \\ \text { FI } & .68292 \\ \text { CUM = CUMMULATIVE } \\ \text { PCT = PERCENTAGE }\end{array}$

FACTOR

1

2

3
EIGEN VALUE CUM PCT

5.4241649 .3
1.6404264 .2
1.4085977 .0 


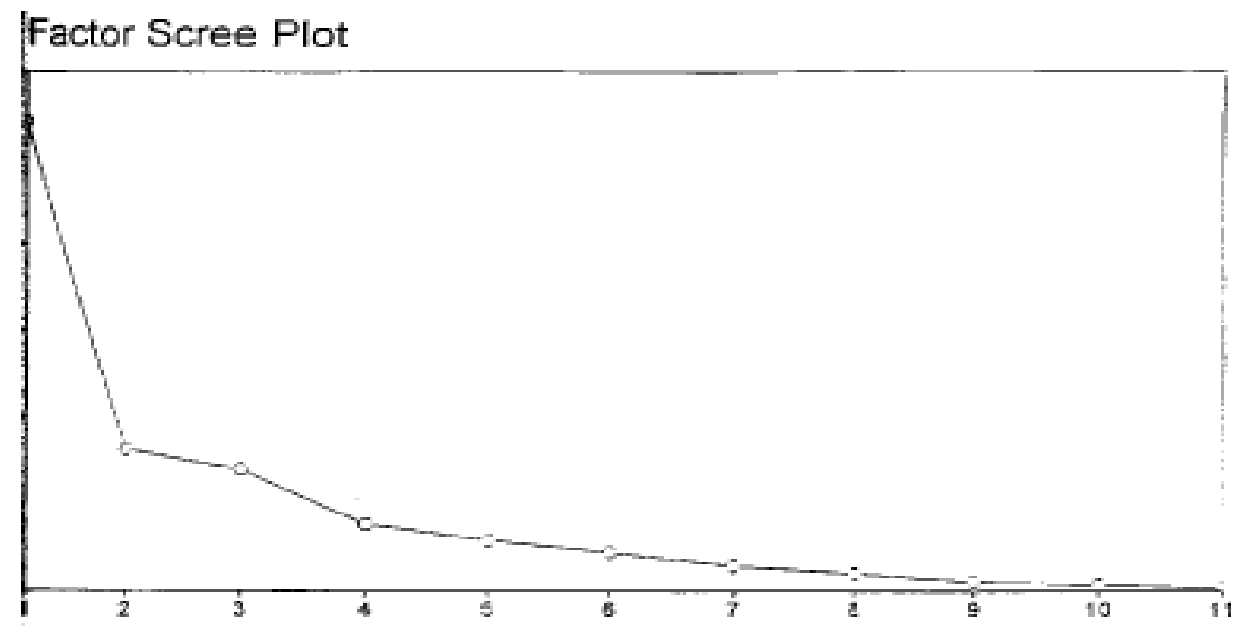

Factor Numiber

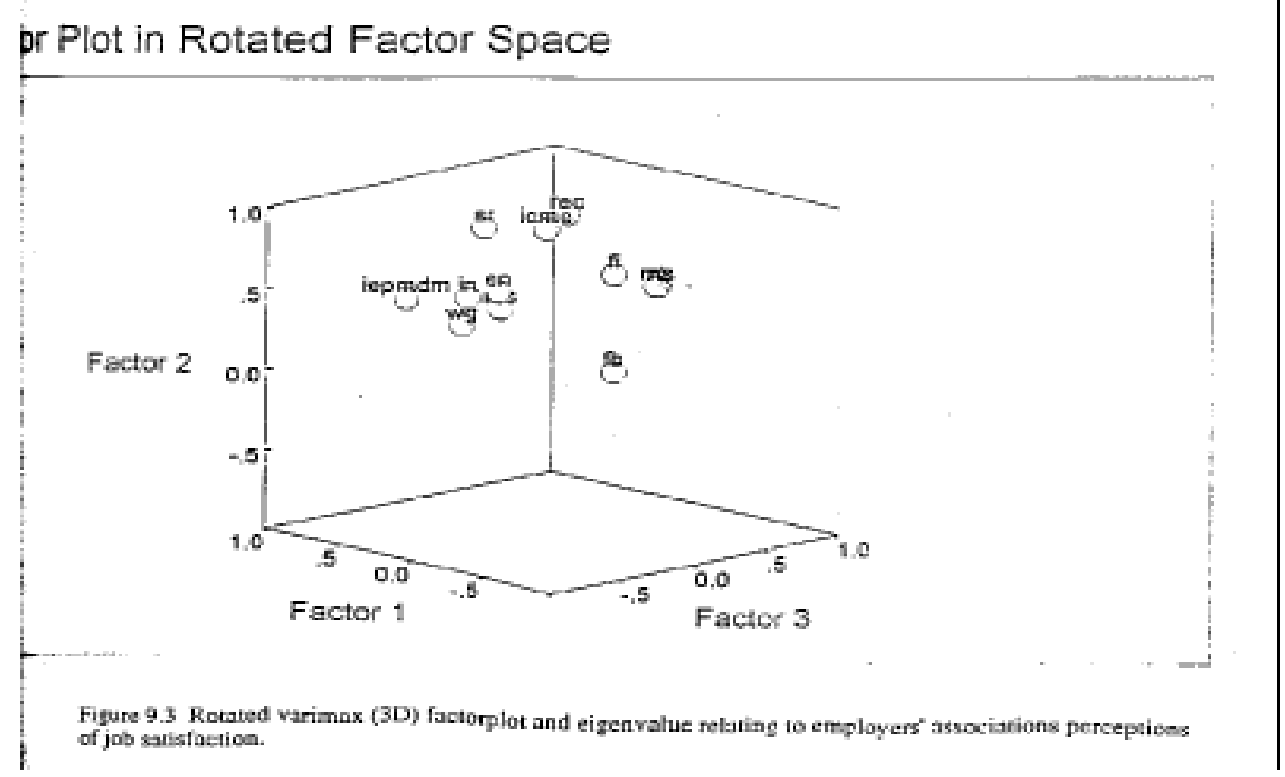

Table 1.4 shows the factor loadings and communality coefficients extracted from the analysis of 16 items relating to the questionnaire for the total sample of union officials while the Figure 1.4 presents the three dimensional plot of the loadings of the first three factors and a scree plot of total variance (Eigen value) associated with each factor. Only three had Eigen value in excess of 0.5 and above and collectively accounting for roughly $87.3 \%$ of the total variance obtained from the related group.

Factor 1 comprises six items representing intrinsic job satisfaction, gained by doing a particular job in a manner determined by employees themselves. These items are connected to specialist term management with minimum management control.Factor 1 can be considered denoting directionality accuracy and influence.Factor 2 consists of six items relating to social satisfaction. These items are plainly internally and externally conferred attributes such as salary, status and responsibility. Factor 2 can be viewed as indicating directionality andmobility aspiration.

Factor 3 comprises two items connected to extrinsic job satisfaction related to rewards. Sometimes rewards demand accuracy of information and maximum supervision. In this regard, employee's satisfaction can only be measured by monetary reward. Factor 3 is evidently related to role accuracy information and "the role maximum supervision" variables. Incentive scheme (IS) and fringe benefit (FB) are associated with lack of trust. In summary these factors can be explained as role accuracy information, role overload andfeedback, all related to workplace communication and industrial relations problems in the construction industry. 
Factor Analysis Of Job Satisfaction In The Construction Industry.

Table 1.4 Factor analysis of items to union officials perception of job satisfaction.

\begin{tabular}{|l|l|l|l|l|l|}
\hline Items & $\begin{array}{c}\text { Loadings } \\
1\end{array}$ & Items & $\begin{array}{c}\text { Loadings } \\
2\end{array}$ & Items & $\begin{array}{c}\text { Loading } \\
3\end{array}$ \\
\hline MS & .82732 & CMUD & .88832 & IS & .88771 \\
\hline JA & .80693 & IEPMDM & .77573 & FB & .83895 \\
\hline WG & .79158 & ICME & .77573 & & \\
\hline SR & .78554 & TS & .76117 & & \\
\hline REC & .69117 & RES & .71403 & & \\
\hline IN & .61757 & ST & .69044 & & \\
\hline
\end{tabular}

ITEM COMMUNITY COEFFICIENTS

$\begin{array}{ll}\text { MS } & .87868 \\ \text { JA } & .80649 \\ \text { WG } & .90354 \\ \text { SR } & .78285 \\ \text { REC } & .81323 \\ \text { IN } & .77560 \\ \text { CMUD } & .93640 \\ \text { IEPMDM } & .95856 \\ \text { ICME } & .95304 \\ \text { TS } & .95807 \\ \text { RES } & .82893 \\ \text { ST } & .84665 \\ \text { IS } & .92599 \\ \text { FB } & .85636 \\ \text { CUM = CUMMULATIVE } \\ \text { PCT = PERCENTAGE }\end{array}$

\section{FACTOR}

1

2

4
EIGEN VALUE CUM PCT

$10.08653 \quad 72$

1.1065980

1.0313387 .3

Factor Scree Plot

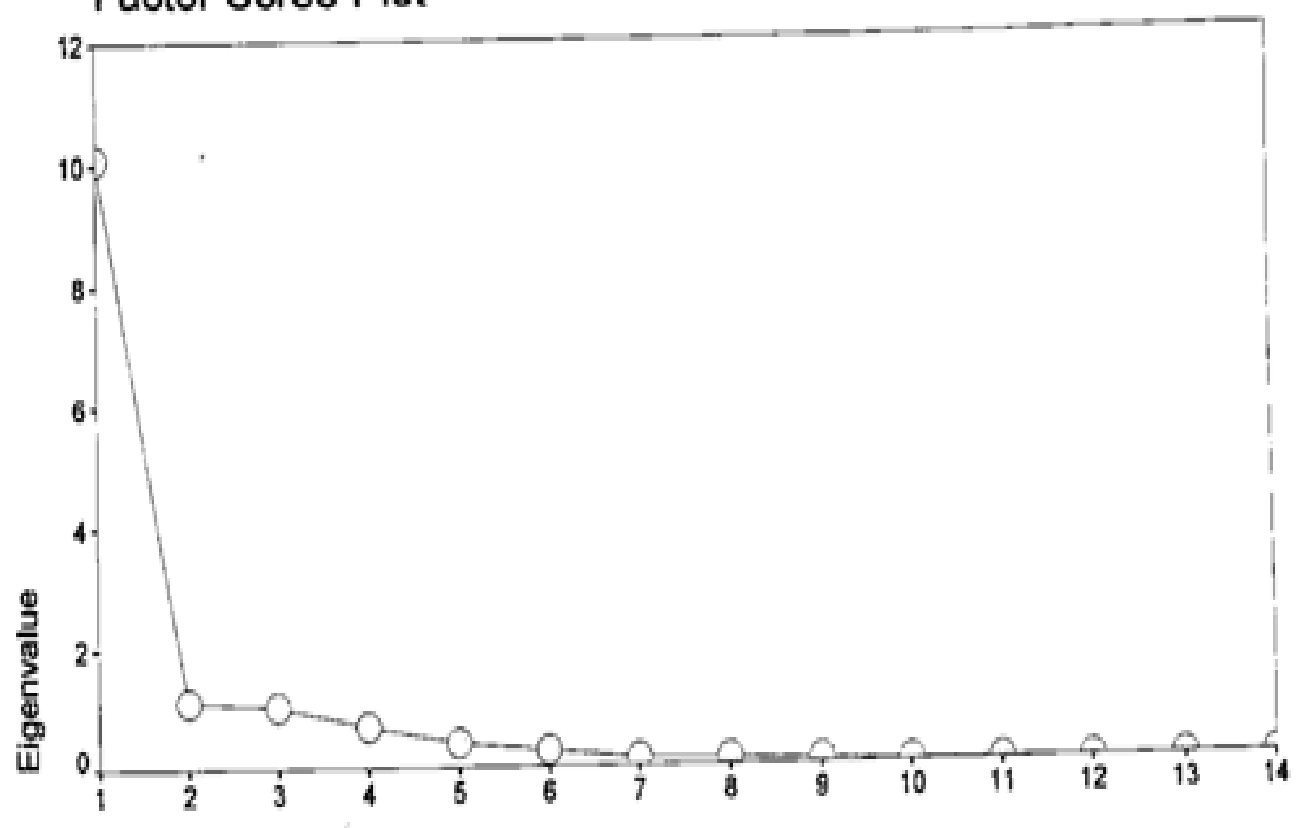

Factor Number 
Factor Plot in Rotated Factor Space

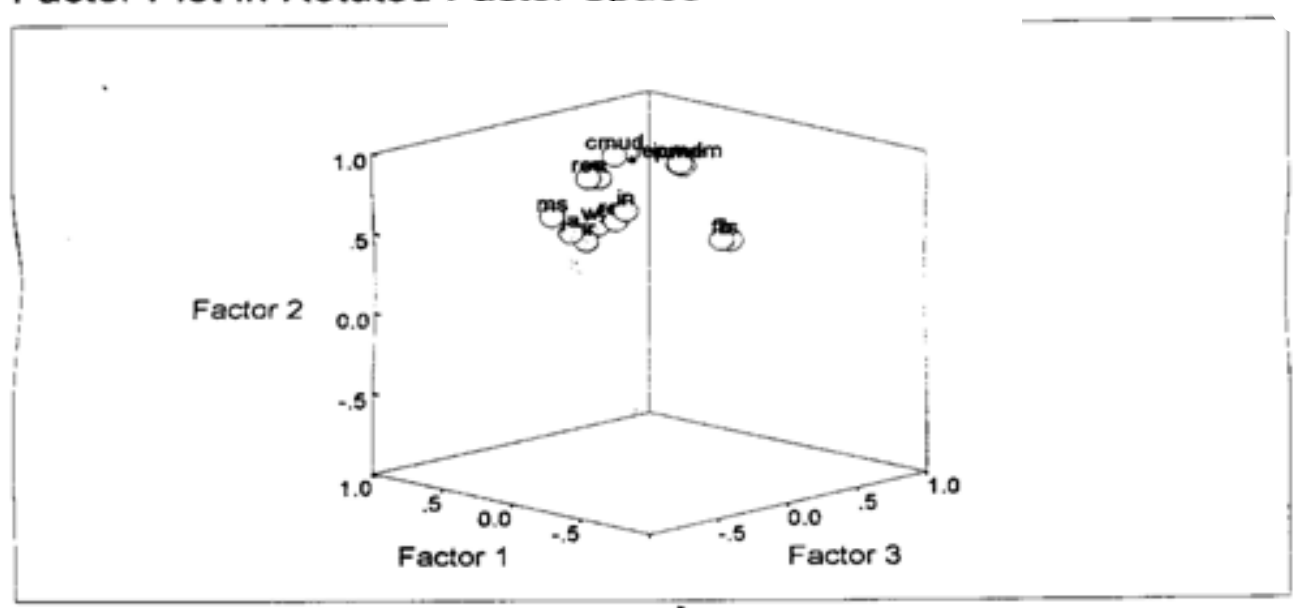

Figure 1.4 Rotated eigenvalue and varimax (3D) factor plot relating to union perceptions of job satisfaction

\section{JOB SATISFACTION COMPARISON}

A detailed description of perceptions of the parties, with special reference of job satisfaction is fundamental importance to this study. It appears that management, the employers' associations, non management employees and the unions have different perceptions of job satisfaction. The results of the factors extracted from the analysis of perceptions of job satisfaction indicate that all factors across the parties are similar with very little difference in the structure of an individual factor. The small difference that are found between the groups relate to the sequencing of the items because of its loadings. The result seems to confirm the third proportions; management, employers association, union and non-management employee (the four construction parties) which will differ in underlying perceptions toward job satisfaction.

Table 1.5 compares the factor analysis results of the parties' perceptions towards job satisfaction. Factor 1 indicates the difference in main perception of the parties towards job satisfaction. Management signifiesthatemployee satisfaction can be reached by giving them freedom with minimum supervision. Employee's see job satisfaction as being concerned with directionality and mobility aspirations. The employers association connects job satisfaction with directionality and influence. The unions, like the employers association perceive job satisfaction as involving directionality and accuracy. This shows the basis of power struggle between two parties (employer's association and worker unions). However, the result appears to support the second proposition. The four major construction parties agree that low level participation by employees in the management decision making process will undermine workplace industrial relations reform.

In factor 2, management regards skill and experience as central to job satisfaction; employee's perception of job satisfaction relate to task and responsibilitiesinvolved in their roles. The employers' association recognizes work behaviour as determining job satisfaction. The union sees job satisfactions as being significantly influenced by mobility aspiration. Similarly, in factor 3 , management indicates responsibility as central to job satisfaction; employees see job satisfaction as resulting from commitment; employers' association regards mobility aspirations and accuracy as a mode of job satisfaction while union sees monetary reward as a principal job satisfaction. Factor 4 indicates directionality, accuracy, skill and experience as central to job satisfaction for employees and management. Theresults show similarities in the perceptions of the four parties, and clearly show that all the factors identified are related to communication.

Table 1.5 Comparison of factor analysis of parties' job satisfaction variables.

\begin{tabular}{|l|l|l|l|}
\hline Management & Employees & Employers' Association & Union \\
\hline Factor 1 & Factor 1 & Factor 1 & Factor 1 \\
\hline Self - managing & $\begin{array}{l}\text { Directionality, } \\
\text { Mobility,Aspiration }\end{array}$ & Directionality, Influence & $\begin{array}{l}\text { Directionality, Accuracy, } \\
\text { Influence }\end{array}$ \\
\hline Factor 2 & Factor 2 & Factor 2 & Factor 2 \\
\hline Skill, Experience & Responsibility & Work behavior & Mobility aspiration \\
\hline Factor 3 & Factor 3 & Factor 3 & Factor 3 \\
\hline Responsibility & Commitment & $\begin{array}{l}\text { Mobility aspiration. } \\
\text { Aspiration }\end{array}$ & Monetary reward \\
\hline Factor 4 & Factor 4 & & \\
\hline Directionality, accuracy & Skill, Experience & & \\
\hline
\end{tabular}




\section{RELIABILITY AND VALIDITY MEASURES}

The aim of reliability and validity measures is to assess the instrument of measures as being valid if it measures what it is intended to measure. Failure to assess the validity of measures may result in research findings that are best misleading. The necessary conditions for validity are reliability.

It is important to see how reliable the results of statistical analyses are, because the scale of data has been used and choice of sample scale could affect the validity. This study focuses on validity of measurement issues as they apply to the data on satisfaction on construction industry.

The reliability of questionnaire data on job satisfaction is reported in Table 1.6 below, draws on the notion of construct validity. Cronbach's Alpha shown in the table is the basic reliability used here. It is based on internal consistency of the test; that is, is based on average correlation of items within the test, the items are standardized to a standard deviation of 1 . The other entry in the table is standardized item alpha value that will be obtained if all the items were standardized to have variance of 1 . Since the items on the research study scale have fairlycomparable variance, there is little difference between the twoalphas indicating that all scales obtained are quite reliable.

Table 1.6 Scale reliabilities.

\begin{tabular}{|l|l|l|}
\hline Employers Association & & \\
\hline Scale & Observed Item Alpha & Standardized item Alpha \\
\hline Management & & \\
\hline Job satisfaction (15 items) & .8079 & .8098 \\
\hline Union & & \\
\hline Job satisfaction (15 items) & .9691 & .9698 \\
\hline Employees & & \\
Job satisfaction (15 items) & .9277 & .9378 \\
\hline
\end{tabular}

\section{CONCLUSION}

The primary objective of this study is to determine if there were any major differences in the perceptions of the four respondent groups towards job satisfaction. His comparison of the four respondent groups at level of factor analysis was fundamentally, important because differences observed in the perceptions show that all respondent groups have not been able to share a common language of operation which is fundamental to the construction industry.

\section{REFERENCES}

[1]. Argyle, M. (1972) The social psychology of Work, HarmondsWorth, Middlesex, England; Penguin.

[2]. Hill, J. M. and Trist, E. L. (1955) "Change in Accidents and other Absences with Length of Services Human Relations8, 121-152.

[3]. Maloney, F. and McFillen (1998) Workers Perceptions of Contractor Behaviour, Journal of ConstructionEngineering; Vol. 113 No 3 ASCE.

[4]. Smith, R. and Roth, D. (1991) Safety Programs and Construction Manager, Journal of Construction Engineering; Vol. 117 No4 360 - 371 ASCE.

[5]. Taffin, J. and McComick, E. J. (1996) Industrial London: Allen \& UNWIN, Basic Book. 